\title{
Gênero e África: outros olhares, outras perspectivas
}

\author{
Gender epistemologies in Africa: \\ gendering traditions, spaces, \\ social institutions and identities. \\ OYWÙMí, Oyèrónké. \\ New York: Palgrave Mcmillan, 2011.
}

"A fim de entender as estruturas de gênero e relações de gênero na África, nós devemos começar com a África".' Esta citação resume o porquê e como encontrei o livro Gender epistemologies in Africa: gendering traditions, spaces, social institutions and identities. Ao buscar fontes bibliográficas sobre feminismo e África, deparei-me com um universo um tanto desconhecido no Brasil, pois, ao longo do meu levantamento de referências, tive dificuldade em encontrar obras na língua portuguesa que abordassem esse tema, podendo trazer teorias e estudos que estivessem sendo feitos neste vasto continente. Logo, surgiu a seguinte pergunta: Por onde começar? Obtive a resposta em uma palestra da professora Cláudia de Lima Costa sobre estudos pós-coloniais e gênero na Universidade Federal de Santa Catarina. Esta professora mencionou o nome da teórica nigeriana Oyèrónké Oywùmí. Felizmente, após algumas pesquisas, encontrei o livro cujo tema será explorado nesta resenha.

Professora de Sociologia da Universidade de Stony Brook, em Nova lorque, Oyèrónké tem como áreas de interesse teorias feministas, sociologia de gênero e conhecimento, estudos africanos, estudos pós-coloniais e modernidades. feminismos transnacionais, e, por fim, teoria social. Dentre suas obras, Oyèrónké foi premiada pelo livro The invention of women: making an african sense of western gender discourses. ${ }^{2}$ Oywùm também é autora do livro African women and feminism: reflecting on the politics of sisterhood ${ }^{3}$ e editora do African Gender Studies. A reader. ${ }^{4}$ Sendo editado por Oyèrónké Oywùmí, o livro Gender epistemologies in Africa: gendering traditions, spaces, social institutions and identities traz um conjunto de 10 artigos sobre gênero referentes a investiga-ções realizadas em diversos momentos históricos e regiões da África, assim como através de diferentes abordagens teóricas e metodológicas, visando compreender a construção das rela-ções de gênero dadas nas interações sociais entre pessoas e instituições.

Os dois primeiros capítulos, "Decolonizing the intellectual and the quotidian: Yorùbá scholars (hip) and male dominance", de Oyèrónké Oywùmí, e "Gender in translation: Efúnsetán Aníwúrà, de Adélékè Adéèko, tratam brevemente sobre traduções errôneas de conceitos sobre gênero em yorùbá para o inglês, apontando que a organização social da comunidade Yorùbá se encontra, atualmente, com herança do pensamento colonizador, o qual tem raízes no sistema patriarcal. Já nos próximos capítulos, o tema abordado é religiosidade, neste caso, o islamismo, e papéis de gênero em comunidades do Senegal e Nigéria. "Ode to patriarchy: the fine line between Praise and Criticism in a popular senegalese põem", de Marame Gueye, tem como enfoque uma crítica literária ao poema popular chamado Fatou Gaye's Song. Gueye aponta que, neste poema, há um discurso sexista e de cunho crítico a Fatou, personagem principal do poema. Tal crítica não se estende somente a esta personagem, mas serve como uma forma de educar as mulheres daquela sociedade dentro do papel que é destinado às mulheres, baseandose em valores proferidos pelo patriarcado através de interpretações de textos islâmicos. O capítulo quatro, "Women and leadership in Nigerian Islam: the experience of Alhaja Sheidat Mujidat Adéoyè of Òsogbo", relata o estudo de caso conduzido por Ogungbile e apresenta a liderança de uma mulher muçulmana, na Nigéria, que está à frente da organização Missão Muçulmana Fadillulah: Alhaja Sheidat Mujidat Adéoyè. O autor descreve como foi o processo de aceitação desta líder dentro da religião islâmica, relatando desde o princípio da sua ascensão, marcada por uma experiência 'divina', até as práticas feitas por Alhaja dentro de sua comunidade.

Em "Engendering critical spatial literacy: migrant asante women and the politics of urban space", Epifania Amoo-Adare mostra o poder da construção de espaços em sociedades africanas os quais não só delimitam as relações, mas também servem como um fator relevante nas formações de identidade de gênero. AmooAdare afirma que essas relações podem definir 
os espaços em que as mulheres podem ser excluídas ou não. Seguindo o tema sobre espaços e identidades de gênero, em "Outsiders within: experiences of women academics in Kenya", Njoki M. Kamau analisa os papéis das mulheres em Universidades no Quênia. O estudo revela que as escolhas de suas carreiras tendem a corresponder ao modelo de divisão de trabalho por sexo masculino e feminino proveniente do patriarcado. Por outro lado, Kamau menciona que estas mulheres são poderosos agentes modificadores destas práticas sociais sexistas, por resistirem dentro de ambiente hostil. No próximo capítulo, "Self-Image and Self-Naming: a social analysis of women's microenterprises in Senegal and Mali", Marieme S. Lo segue um debate similar, abordando o tema de mulheres e suas carreiras como empreendedoras, nos países Senegal e Mali. De acordo com Lo, sua análise procura compreender as "características emergentes, fluidas, e similares de microempresas de mulheres que abrangem os domínios sociais, econômicos e políticos, ampliando assim a sua taxonomia". ${ }^{5}$

Os três últimos artigos partilham da mesma área de estudos: História. O texto "Irua Ria Atumia and anticolonial struggles among the Gekfyf of Kenya: a counternarrative on 'Female Genital Mutilation"' apresenta um contraponto ao discurso de opressão sobre os rituais de mutilação de genitálias femininas, apontando que estas práticas foram utilizadas como forma de empoderamento e resistência contra o sistema colonial no Quênia. Wairimú Ngarúya Njambi descreve os rituais de irua ria atumia na anake (um ritual de iniciação para mulheres e homens aos 16 e 18 anos) na comunidade Kikuyu, conhecidos como rituais da 'circuncisão feminina controversa', os quais foram usados como manifestação política anticolonial na década de 20, até a revolta de Mau Mau nos anos 50.) (NJAMBI, 2011 ) Njambi propõe uma reflexão sobre o discurso predominante de dominação e submissão das mulheres aos homens nas práticas culturais de determinados povos, alegando que não devemos nos ater somente a esses discursos para compreendermos tais práticas, mas devemos observar que estes grupos podem ser "agentes (dos rituais) nos quais estrategicamente se reinventam".6

No capítulo nove, "NAKABUMBA: God creates humanity as a potter creates a pot", Cristine Saidi sugere uma nova leitura sobre a interpretação de estudiosos da historia précolonial ao explicarem as relações de gênero no processo de produção de cerâmica em países como Zâmbia, Congo e oeste de Malawi. Sendo uma fonte econômica de suma importância dessas regiões, Saidi faz uma triangulação de sua análise ao focar no processo de produção das cerâmicas, nos ceramistas, e o significado social dessas peças à comunidade. O mesmo apelo para uma releitura das interpretações oci-dentais sobre as relações de gênero e a divisão de trabalho na África está presente no último artigo apresentado. Em "Beyond gendercentric models: restoring motherhood to Yorùbá discourses of art and aesthetics", Oywùmí afirma que há pressupostos nos discursos de do-minância em estudos sobre a África no Ocidente, os quais induzem às interpretações da vida africana e dos artefatos culturais como centra-lizados na divisão de gênero. ${ }^{7}$ Seu argumento baseia-se em sua análise de artefatos provindos da cultura Yorùbá, cuja organização não era baseada em marcas de gênero. Oywùmí conclui que as descrições da divisão do trabalho na história conhecida sobre a África foram resultado de análises e interpretações de seus colonizadores, sob um olhar sexista e de domi-nância masculina. Como exemplo, a autora cita que estes historiadores pré-julgavam que os ar-tistas desconhecidos de inúmeros artefatos eram homens, mesmo sem conhecer que as práticas ritualistas e filosóficas em yorùbá centralizam-se na questão da criação e da maternidade. Por-tanto, muitos 'dos artistas' desconhecidos eram mulheres.

Levando em consideração alguns aspectos brevemente mencionados de cada trabalho deste livro, é possível afirmar que tais estudos partem do princípio de que a categoria gênero não é somente socialmente construída, mas também é historicamente localizada. De acordo com Oywùmí, ${ }^{8}$ os estudos sobre a África relacionados ao gênero não devem ter como premissa os discursos do conceito de gênero predominantes em diversas sociedades ocidentais, os quais definem que tal categoria é 'trans-histórica' e 'essencialista'. Desta forma, Oywùmí aponta a importância de investigações que visam analisar criticamente as interações sociais de modo de a compreender como as relações de gênero emergiram, considerando um dado período histórico em sociedades africanas, assim como também analisar o significado do gênero nestes contextos e a maneira com que as relações de desigualdade de gênero são mantidas e propagadas. Conforme proposto pela autora, "gênero é, na verdade, mais sobre performatização-um processo - do que algo inerente nas relações sociais". 9

Esta questão - sobre a importância da abordagem atenta à historicidade em estudos de gênero e África - é perceptível ao longo da exposição de cada estudo. Por exemplo, no primeiro 
capítulo do livro, Oywùmí analisa as relações de poder no meio acadêmico onde são conduzidos estudos sobre a comunidade Yorùbá, assim como na própria comunidade. Ela busca compreender o processo de internalização da dominância masculina em ambas as esferas, apontando que tal processo foi recentemente incorporado nestas comunidades sob influência das categorias de gênero impostas pelas sociedades colonizadoras. Ao exemplificar seu raciocínio, Oywùm cita a distorção nas traduções de epistemologias sobre o corpo em yorùbá para o inglês, pois, segundo a autora, houve uma tradução errônea em termos que em yorùbá não carregam marcas de gênero e que foram masculinizados na língua inglesa. O mesmo processo ocorreu com outros termos, nos quais figuras femininas nas crenças em yorùbá foram demonizadas ao serem aproximadas ao conceito de 'bruxas', carregando um significado intenso como figuras do mal. Porém, na própria cultura yorùbá, estas figuras não carregam tal significado.

Outro exemplo a citar é o texto de Adélékè Adéèko, que aprofunda a questão de traduções de textos das categorias de gênero em yorùbá para $\circ$ inglês, apontando as reações de estranhamento destas traduções na cultura Yorùbá Tendo como evidências textuais duas peças de teatro e um filme que reportam à vida de uma importante figura feminina no sudoeste da Nigéria, Adéèko analisa suas representações, mostrando que há uma influência no Cristianismo na formação de crenças, valores e categorização proferida nessas representações. Ambos os pesquisadores propõem um olhar aos costumes e tradições como um processo descolonizador de uma sociedade patriarcal que se efetivou atualmente.

Ambos os textos descritos acima me fizeram refletir sobre alguns pontos pertinentes provindos da minha formação identitária. Sendo uma praticante da religião Afro-Gaúcha Nação, uma religião afro-brasileira cujos costumes vieram da comunidade Yorùbá, da Nigéria, a problematização sobre as categorias de gênero me remeteram à dificuldade que muitos de nós, praticantes, temos em explicar a um leigo no assunto sobre os 'corpos' que representam os Orixás, pois, de fato, existem orixás que não possuem marca de gênero feminino ou masculino, como, por exemplo, Oxumaré. Além disso, esta dificuldade de elucidação também ocorre até mesmo entre nós, membros desta comunidade religiosa. Muitos devotos explicam que Oxumaré é um orixá que é seis meses do sexo feminino; outros seis meses ele é do sexo masculino, fazendo com que, desde pequena, essa representação me causasse estranheza. Lendo esses textos, pude concluir que esta necessidade de categorização provém da sociedade em que vivemos e nos constituímos como sujeitos, fortemente permeados por relações dicotômicas de gênero, e que (ainda!) privilegiam um modelo de dominação e poder dos homens.

Para finalizar, acredito que a leitura deste livro passa a ser essencial para qualquer indivíduo interessado em estudos de gênero. O motivo que me faz crer em tal importância também é explorado por Zahra Ali, em Femmes, féminism et islam: décoloniser, d'ecloisonner et renouveler le féminisme. ${ }^{10} \mathrm{Em}$ seu texto, esta autora defende a desconstrução do discurso dominador sobre a existência da submissão feminina em sociedades 'não ocidentais', o qual ainda tende a classificar o outro sob uma visão dicotomizada (bom $X$ ruim) como: 'os ocidentais estamos mais próximos da igualdade de direitos, enquanto os outros cultuam um modo de vida bárbaro'. Assim como Oywùmí, Ali também acredita que tal discurso provém de uma construção histórica, sendo que, neste caso, Ali relata sobre o conceito da mulher islã em discursos ocidentais, os quais a tomam como submissa e inferior, não dando abertura para uma reflexão do que é ser uma mulher islâmica considerando seu status na atualidade, muito menos dando espaço para representações plurais sobre sua identidade. Neste sentido, é perceptível a urgência de publicações que divulguem esses diversos olhares, pois a pluralidade de feminismos é, de fato, existente e inegável.

Notas

' Oywùmí, 201 1, p. 2 [tradução minha]

${ }^{2} 1997$.

${ }^{3} 2003$.

${ }^{4} 2005$.

${ }^{5}$ 2005, p. 157 [tradução minha].

- Oywùmí, 201 1, p. 6.

7 Oywùmí, 2011 , p. 223.

${ }^{8} 2001$.

9 Oywùmí, p. 2 [tradução minha]

${ }^{10} 2012$.

\section{Referências}

ALl, Zahra. Femmes, féminism et islam: décoloniser, d'ecloisonner et renouveler le feminism. Font du 20 Mars, 2012.

OYwÙMí, Oyèrónké. Gender epistemologies in Africa: gendering traditions, spaces, social institutions and identities. New York: Palgrave Mcmillan, 2011.

Litiane Macedo

Universidade Federal de Santa Catarina 